\title{
O narrador em Corinthians (2) VS. Palestra (1): (im)parcialidade?
}

\section{The narrator in Corinthians (2) VS. Palestra (1): (im)parciality?}

\author{
James Rios de Oliveira Santos ${ }^{*}$ \\ jamestimao@hotmail.com \\ Universidade Estadual do Norte do Paraná \\ Tiago Angelo* \\ tiago-angelo@hotmail.com \\ Universidade Estadual do Norte do Paraná
}

\begin{abstract}
RESUMO: O presente trabalho objetiva apresentar uma leitura do conto Corinthians (2) VS. Palestra (1), de Alcântara Machado. Texto de grande vigor narrativo, o conto em apreço abre margem para estudos desta natureza dada à linguagem radiofônica mobilizada pelo narrador para a condução dos fatos, uma vez que as marcas linguístico-enunciativas sugerem a torcida do narrador para um dos times de futebol. Pesquisa de natureza bibliográfica, este artigo faz uso do método qualitativo para propor uma leitura que evidencie a imparcialidade do narrador ante o jogo entre Corinthians e Palestra. No curso da análise realizada, constatou-se que o narrador revela-se corintiano, o que o torna uma instância ficcional parcial. Com intuito de atestar tal parcialidade, este estudo mobiliza estudos teóricos e críticos acerca do foco narrativo, tais como o de Norman Friedmann (2002), Wayne Booth (1980) e Davi Arrigucci Jr. (1998).
\end{abstract}

PALAVRAS-CHAVE: Literatura. Futebol. (Im)parcialidade.

ABSTRACT: This paper aims to present a reading of the short story Corinthians (2) VS. Palestra (1) by Alcântara Machado. The narrative is a text of great narrative force, which opens up opportunities for studies of this nature given the radiophonic language mobilized by the narrator to conduct the facts as the linguistic-enunciative marks suggest that the narrator supports one of the soccer teams. This qualitative research study proposes a reading to evidence the impartiality of the narrator throughout the game between Corinthians and Palestra. However, during the analysis, we found that the narrator reveals himself to be a Corinthians fan, which makes him a partial fictional instance. In order to attest such partiality, this study mobilizes theoretical and critical studies about the narrative focus, such as the ones by Norman Friedmann (2002), Wayne Booth (1980), and Davi Arrigucci Jr. (1998).

KEYWORDS: Literature. Soccer. (Im)parciality.

\footnotetext{
* Mestre em Letras, com ênfase em Estudos Literários, pela Universidade Estadual de Maringá. Professor do curso de especialização em Humanidades, da Universidade Estadual do Norte do Paraná (UENP).

* Especialista em Estudos Linguísticos e Literários pela Universidade Estadual do Norte do Paraná. Assessor de Comunicação Social, da Universidade Estadual do Norte do Paraná.
} 


\section{Considerações Iniciais}

Este artigo tem a pretensão de ser um esforço reflexivo sobre os aspectos estruturais, mais precisamente acerca do narrador do conto Corinthians (2) VS. Palestra (1), de Alcântara Machado. O texto, que integra a coletânea de contos intitulada Brás, Bexiga e Barra Funda, apresenta algumas implicações acerca do narrador, que julgamos merecedoras de uma análise que possa, além de tentar empreender uma leitura mais acurada sobre o assunto, observar, de perto, como esse personagem conduz a narrativa, considerando-se a prerrogativa deste narrar (também) uma partida de futebol.

É preciso ressaltar que o texto em tela nos interessa porque, publicado em 1928, está didaticamente inserido na escola modernista, cuja estética se orienta para o incentivo da tematização da sociedade nacional na literatura e para o rompimento com o convencionalismo linguístico utilizado tanto na poesia quanto na prosa das escolas literárias anteriores. Por estes motivos, pressupomos que tanto o futebol, uma paixão de muitos brasileiros, quanto a narração radiofônica se tornaram matéria temática a ser explorada por Alcântara Machado. Sendo o futebol um assunto de relevância para boa parte da sociedade brasileira devido às paixões que congrega, entendemos que pode justificar a escolha da temática esportiva e o recurso linguístico utilizado pelo autor para compor a diegese.

Para que possamos lograr êxito em nossa reflexão analítica, propomos trazer, à baila desta discussão, uma reflexão sobre a abordagem do futebol enquanto matéria literária para, em seguida, debruçarmo-nos, com maior propriedade e melhor entendimento em algumas considerações tangenciais às implicações do narrador, orientados por autores como Françoise van Rossum-Guyon ([1976]), Norman Friedmann (2010), Wayne Booth (1980) e Davi Arrigucci Jr. (1998), além de outros teóricos e críticos que versam sobre o assunto.

\section{0 futebol entre as linhas: um gol para a Literatura Brasileira}

Segundo Damatta (1994), o futebol, esporte trazido para o Brasil no final do século XIX por meio de um documentado processo de difusão cultural, foi primordialmente praticado pelas elites, mais precisamente por estrangeiros aristocráticos que estavam ligados a uma gama de investidores europeus, os quais, 
no bojo de suas intenções, buscavam explorar oportunidades que se encontravam abertas em um país em desenvolvimento nesse século. No entanto, a problemática do futebol elitista eclodiu quando os operários e negros "passaram a ser decisivos para que os times de brancos ricos ganhassem títulos" (GUTERMAN, 2009, p.10). Daí a justificativa para a inserção cada vez mais assídua da massa trabalhadora que encontrou, nesse esporte, um possível acesso à tão negada democracia.

Entre um jogo e outro, podemos afirmar, em primeira instância, que o esporte bretão - e agora brasileiro - foi rumando à profissionalização. Esse fato é visivelmente observado por meio das inúmeras competições que atraíam, nos campos de várzea, uma quantidade significativa de público que acirrava, de maneira incisiva, as partidas, o que nos leva a entender que, embora lentamente, o esporte ensaiava alguns passos profissionais, pois "os melhores jogadores passaram a ser disputados e remunerados por clubes cada vez mais interessados em competir para vencer" (GUTERMAN, 2009, p.10).

O futebol, Guterman (2009, p.09) salienta, tornou-se um dos maiores fenômenos sociais do Brasil e, dentro desse contexto, "representa a identidade nacional", pois essa relação "de tão forte, é vista como parte da própria natureza do país". Logo, compreendemos que essa manifestação esportiva serviria, mais cedo ou mais tarde, como temática a ser desenvolvida dentro de uma literatura que, no momento áureo da Semana de 22, ganharia incisivas contribuições estéticas que foram ao seu encontro. O contista Alcântara Machado não só se insere no período em que o futebol se instala no país, como se apropria de seu contexto sociohistórico e faz dele uma nova temática para a literatura brasileira que, até então, não havia sido explorada.

Autor de vida breve (falecido aos 34 anos), Alcântara não pôde prolongar sua produção artística. No entanto, foram quatro obras literárias (Pathé Baby, Brás Bexiga e Barra Funda, Laranja da China, Mana Maria) e um ensaio (Cavaquinho e Saxofone) que merecem, segundo a crítica, a devida atenção, já que, como acentua Bosi (2006), esse autor foi um dos mais importantes escritores da primeira geração modernista devido à tamanha contribuição que deu para a disseminação de novos ideais de literatura.

Dentre as contribuições significativas de A. Machado para o modernismo brasileiro, podemos afirmar, com respaldo em Bosi (2006, p.401), que sua consagração enquanto autor reconhecido pela academia se dá com a publicação de 
Brás, Bexiga e Barra Funda, em 1928. Esta obra apresenta, entre outros importantes aspectos, a luta do italiano para conseguir seu dinheiro, sua ascensão social e o despreparo da cidade paulistana para acolhê-lo.

É-nos visível que o autor modernista traz, para o plano da narrativa literária, a sua realidade ítalo-paulista, pois é "voltado para a vida da sua cidade que Alcântara Machado soube ver e exprimir as alterações que trouxera à realidade urbana um novo personagem: o imigrante" (BOSI, 2006, p.400). Este, por sua vez, compõe o cenário figurativo do conto Corinthians (2) VS. Palestra (1), que apresenta a história de Miquelina e, concomitantemente, uma partida de futebol entre dois times arquirrivais: Corinthians e Palmeiras.

Compreendida, pois, essa relação entre o futebol e a literatura, é preciso atentar para a figura do narrador - recurso ficcional de extrema relevância para o escritor, mas que se encontra envolto por uma série de implicações que iremos tratar mais adiante. O que nos importa, neste momento, é chamar atenção para esse sujeito que, no conto em análise, está inserido num contexto esportivo, narrando uma partida de futebol, a qual "só admite dois sentimentos fortes e antagônicos: o amor e o ódio" (COSTA, 1994, p. 85). Diante desse fato, convém-nos lançar as seguintes perguntas: Como se porta, então, esse narrador diante desses sentimentos? Ele mantém-se imparcial nos relatos dos fatos? Todas as cenas são narradas com a mesma intensidade? Há marcas linguísticas que possam aludir a uma imparcialidade? Essas e outras questões constituem o cerne de nossa discussão, que pretendemos problematizar.

\section{As implicações do narrar: algumas (im)possibilidades}

O narrador ficcional merece um olhar atento porque, desde o Realismo, tem assumido condutas diversas que nos permitem entrever a sua ideologia, posição social entre outros fatores que o fazem conduzir o enredo de maneira pretensiosa (DALCASTAGNĖ, 2000). Mas os problemas concernentes a esse sujeito têm raízes mais profundas, mais substanciais, que geraram, no curso da história da literatura, questionamentos (que ainda se mantém em aberto) de ordens diversas como, por exemplo, a possibilidade de se narrar qualquer história na contemporaneidade (ARRIGUCCI, 1998). Comecemos por Walter Benjamin, que propõe essa discussão em âmbito teórico. 
Benjamin (1994), em seu ensaio intitulado O narrador (1936), postula que a decadência da narrativa justifica-se pelo fato de os homens terem deixado de trocar experiências entre si, devido ao "desaparecimento da narrativa oral, uma faculdade 1 aparentemente inerente ao homem e comum a todas as sociedades, que entra em declínio quando vai desaparecendo a matéria de que nutre a tradição oral: a experiência veiculada boca a boca" (ARRIGUCCI JR., 1998, p.30). Nesse sentido, reforça Benjamin (1994) que, com a decadência da narrativa, está em declínio também a figura do narrador - sujeito responsável pelo intermédio entre a experiência e os interlocutores - com a ascensão do romance: gênero que orienta o leitor para uma atividade solitária. Criou-se então, a partir da daí,

um mal-estar da narrativa registrada tanto na teoria quanto na prática dos narradores, e isso de algum modo vem juntar-se também a essa desconfiança quanto à narrativa que se observou em certo momento deste século e que está patente nessa rachadura entre o discurso narrativo e os fatos narrados, entre o discurso e a história, formulada tantas vezes em nosso tempo (ARRIGUCCI JR., 1998, p.31).

As reflexões de Walter Benjamin vão, em certa medida, ao encontro das proposições de Theodor Adorno quando este, a exemplo, compreende que as catástrofes da Guerra provocaram a mudez naqueles que dela participaram, impossibilitando, assim, o intercâmbio de experiências (ADORNO, 2003). Não obstante, vale ressaltar que o crítico da Escola de Frankfurt dirige sua discussão acerca do narrador a partir do paradoxo que se interpõe no momento em que a estrutura romanesca exige "o narrar" quando não se é mais possível, uma vez que o declínio do Realismo provocou a ascensão da subjetividade. Nas palavras de Arrigucci Jr. (1983, p.30), a "impossibilidade de um realismo de fachada leva o romance à busca de um realismo de essência, que vá além da realidade reificada, defrontando-se então com o paradoxo de ter que narrar, numa época em que isto se apresenta como uma impossibilidade".

Em Teoria da Narrativa: Posições do Narrador (1998), Davi Arrigucci Jr., ao supor a possibilidade de narrar, apresenta uma multiplicidade de problemas que constitui a base da técnica ficcional, dentre eles, o problema do tom e o do ponto de

\footnotetext{
${ }^{1}$ Essa "faculdade", a que se refere Benjamin (1994), está intrinsecamente relacionada à necessidade de se promover o ensinamento, considerando-se o fato de que a experiência encontra a sua base no bojo de um ambiente coletivo, que espera, nas figuras do viajante e do camponês, o compartilhamento dos saberes de outrem.
} 
vista. No que tange ao primeiro, o autor salienta que aquele pode ser compreendido como a atitude que o narrador se antepõe ao fato a ser narrado, ou seja, o modo como ele irá conduzir a história, aferindo-lhe certo grau de ironia, quando em narrativa escrita, ou promovendo a entoação da frase, quando em narrativa oral.

Em linhas gerais, a noção do ponto de vista pode ser compreendida, na perspectiva em que fala Arrigucci Jr. (1998), como as questões concernentes aos problemas do narrador, mais objetivamente na relação existente entre este e o objeto narrado. Mas estas questões, conforme posto anteriormente, estão, ainda hoje, em aberto no âmbito teórico, dado às constantes proposições e renovações que sucederam em países como Inglaterra, Estados Unidos e Alemanha, desde o início do século XX (ROSSUN-GUYON, [1976]). No entanto, é preciso ressaltar que foi Aristóteles quem propôs, pela primeira vez, essa discussão em Poética. Lembra Arrigucci Jr. (1998, p.13) que, precisamente no livro III dessa obra, o filósofo, ao se referir à arte da imitação, compreende que um mesmo objeto pode ser imitado de maneiras diferentes, ou seja, "pode-se imitá-lo contando simplesmente (pela boca de um terceiro como faz Homero ou mantendo a própria personalidade sem mudar), ou demonstrando as pessoas agindo, como 'em ato'. Entendemos, assim, que há, pelo menos, dois modos de se iniciar uma história: narrando de maneira indireta um fato ocorrido ou mostrando de modo dramático o mesmo fato em forma de cena, o que, nas palavras de Aristóteles, podem ser chamados de "panorama e cena".

A proposição de Aristóteles aproxima-se muito das terminologias "sumário" e "cena" propostas pelo crítico norte americano Norman Friedman, em artigo publicado na década de 1950 - O ponto de vista da ficção. Nessa obra, o autor concebe a narração indireta como sumário e a cena como sendo um modo dramático de se "narrar" um fato. Desse modo, o sumário consiste no relato genérico de diversos acontecimentos em que o enunciador compila uma quantidade significativa de informações dos actantes ${ }^{2}$, sintetizando ações ocorridas em diversos tempos e espaços, "como é bastante comum no flash-back, que pode nos dar os antecedentes ou a vida regressa de uma personagem" (ARRIGUCCI JR., 1998, p.14). A cena, por sua vez, exige um detalhamento mais substancial das ações, detendo-se na

\footnotetext{
${ }^{2}$ Emprestamos do semioticista russo, Algirdas Julien Greimas, o termo actante para nos referirmos aos personagens da narrativa.
} 
caracterização das personagens, na precisão do tempo e do espaço, bem como na demonstração dos diálogos.

Embora o sumário e cena constituam dois modos diferentes de se narrar uma história, vale ressaltar que, no plano diegético, eles são elementos interdependentes, pois, segundo Arrigucci Jr. (1998), ainda que um autor privilegie uma dessas possibilidades, há sempre a necessidade de se remeter o sumário à cena ou vice-versa, uma vez que não há um modo puro de narração. Observemos, no excerto abaixo, um exemplo nas próprias palavras do estudioso:

Se lerem, por exemplo, "Hills like white elephants", que é um conto famoso de poucas páginas, encontrarão basicamente o diálogo de um casal no vale do Ebro na Espanha, rodeado pelas colinas brancas referidas no título da short story: o homem, um norteamericano, e uma mulher chegam a uma estaçãozinha perdida, num dia de calor e sem sombra, pedem duas cervejas, começam uma conversa aparentemente banal, mas desencontrada e tensa, num crescente dramatismo, que vai revelando em cada detalhe particular os complexos e delicados problemas da relação afetiva, o conflito do casal em torno de um eventual aborto que a moça vai ou não fazer. Isso tudo, de forma alusiva e velada ao longo da cena continuada, precedida apenas pela breve descrição local e pelos rápidos movimentos finais do homem no bar da estação, antes da chegada do trem que os levará a Madri e do fim do diálogo, com a aparente reconciliação do casal. O continho se resume nisso: numa cena direta, com um mínimo de sumário, o qual, no entanto, enquadra a conversa e provavelmente the confere um aspecto simbólico [...] (ARRIGUCCI JR., 1998, p.14-15).

Em face ao exposto, é-nos evidente a necessidade do sumário ainda que a preferência do contista seja o modo dramático de narrar. O mesmo ocorre quando, por outro lado, o escritor toma o sumário como meio de condução de sua narrativa: ele não pode sintetizar as partes da história sem apresentar cenas concretas.

Compreendida, pois, a especificidade de cada possibilidade narrativa, convém-nos agora problematizar a escolha desses modos narrativos pelo autor: $O$ que o leva a escolher um modo de narrar em detrimento de outro? Recorremos a Henry Fielding, romancista inglês do século XVIII, para elucidar essa questão:

Quando se nos apresentar alguma cena extraordinária (como nos fiamos de que seja muita vez o caso), não pouparemos esforços nem papel para referi-la miudamente aos nossos leitores: mas se anos inteiros derivarem sem que nada suceda digno de atenção, sem receio das soluções de continuidade, aos assuntos de importância, e 
deixaremos totalmente despercebidos tais períodos de tempo (FIELDING ${ }^{3}$ apud ARRIGUCCI JR., 1998, p.15).

A colocação de Fielding é clara: um autor escolhe a cena quando se quer narrar fatos potenciais, concretos, aquilo que é de maior importância para sua história. As informações que não lhes interessam - por algum motivo - tornam-se, no plano da narrativa, menos imprescindíveis e, por isso, não são dignas de atenção, sendo logo sintetizadas em breves sumários. Vejamos, pois, como se dá esse processo em Corinthians (2) VS. Palestra (1).

\section{Corinthians, Palestra e o Autor: a (im)parcialidade}

O conto elegido nesta análise estrutura-se, predominantemente, por meio de cenas. Isto acontece porque, antes de qualquer coisa, o narrador se empenha em narrar uma partida de futebol, o que pressupõe uma descrição das jogadas realizadas pelos personagens, no caso, os jogadores que compõem os elencos de Corinthians e Palestra. Mas o foco narrativo ${ }^{4}$, no entanto, não se restringe apenas ao campo de futebol, uma vez que focaliza também Miquelina, a protagonista do conto. No fragmento abaixo, podemos observar o narrador descrevendo uma jogada iniciada por um dos jogadores, Melle, que recebe a bola na "extrema esquerda" do campo e avança em direção ao gol adversário.

\section{- Aí, Heitor!}

A bola foi parar na extrema esquerda. Melle desembestou com ela.

A arquibancada pôs-se em pé. Conteve a respiração. Suspirou:

- Aaaah!

Miquelina cravava as unhas no braço gordo da lolanda. Em torno do trapézio verde a ânsia de vinte mil pessoas. De olhos ávidos. De nervos elétricos. De preto. De branco. De azul. De vermelho (MACHADO, 2012, p.41-42).

\footnotetext{
${ }^{3}$ Citação da obra The history of Tom Jones, a foundling de Henry Fielding. Citação no original: "When any extraordinary scene presents itself, (as we trust will often be the case) we shall spare no pains nor paper to open it at large to our reader; but if whole years should pass without producing anything worthy his notice, we shall not be afraid of a chasm in our history; but shall hasten on to matters of consequence, and leave such periods of time totally unobserved" (1985[1749], p. 88).

Reference: FIELDING, H. The history of Tom Jones, a foundling.London: Penguin Classics, 1985[1749].

${ }^{4}$ Assim como Arrigucci Jr. (1998), entendemos a noção de foco narrativo como sinônimo de ponto de vista.
} 
Não há, aqui, uma síntese de um acontecimento - ou um sumário, que seja principalmente no caso da protagonista, pois o narrador apresenta detalhes específicos do momento (da ação) em que Miquelina, tomada pela adrenalina do jogo, crava suas unhas nos braços de lolanda para conter sua ansiedade.

E a trama é apresentada assim: quase toda por meio de cenas, intercaladas com alguns sumários - bem poucos, podemos dizer - que servem, na verdade, de contextualização para o leitor acerca de um fato, como demonstra o seguinte excerto: "Era mesmo. Gostava do Rocco, pronto. Deu o fora no Biagio (o jovem e esperançoso esportista Biagio Panaiocchi, diligente auxiliar da firma desta praça $\mathrm{G}$. Gasparoni \& Filhos e denodado meia-direita do S. C. Corinthians Paulista, campeão do Centenário) só por causa dele" (MACHADO, 2012, p.43). Após esse sumário, o leitor, certamente, compreenderá a atitude da personagem ante a partida de futebol e perceberá que ela possui um motivo a mais para torcer pelo Palestra Itália: Biagio, seu ex-namorado, é atleta do time alvinegro, o que eleva o nível de tensão de Miquelina para além da rivalidade que Corinthians e Palmeiras ${ }^{5}$ é capaz de proporcionar em uma partida de futebol. Isto pode ser comprovado por meio desse outro sumário em que o narrador apresenta, brevemente, um resumo da origem do conflito entre os dois actantes: "Na Sociedade Beneficente e Recreativa do Bexiga toda a gente sabia de sua história com o Biagio. Só porque ele era frequentador dos bailes dominicais da Sociedade não pôs mais os pés lá. $E$ passou a torcer para o Palestra. E começou a namorar o Rocco" (MACHADO, 2012, p.43).

As passagens referentes ao conto de Alcântara Machado ratificam a proposição de Arrigucci Jr. (1998) que, fundamentada em Norman Friedman, compreende a relação de interdependência existente entre esses dois modos de narrar. Contudo, o que nos instiga nesta discussão é o critério utilizado pelo autor para detalhar determinadas cenas do jogo, pois, no contato com a obra, o leitor atento certamente notará uma ênfase maior (do narrador) às jogadas do time corintiano em detrimento dos breves apontamentos e indicações que sugerem as movimentações dos jogadores e até mesmo o gol da equipe palestrina.

O primeiro gol do Corinthians, por exemplo, é demonstrado no texto com intensidade pelo narrador, uma vez que este procura descrever o percurso de Neco

\footnotetext{
${ }^{5}$ Após a adesão do Brasil à Segunda Guerra Mundial, o governo brasileiro determinou as mudanças dos nomes que fizessem menção direta ou indiretamente aos países do Eixo, ou seja, à Itália, ao Japão e à Alemanha. Desse modo, a Societá Sportiva Palestra Italia passou a se chamar Sociedade Esportiva Palmeiras - termo que também utilizamos para nos referir ao time do Palestra.
} 
até a trave adversária e, o mais importante, o momento da finalização do gol: "[...] Parecia um louco. Driblou. Escorregou. Driblou. Correu. Parou. Chutou" (MACHADO, 2012, p.42). Ainda que o segundo gol seja narrado de maneira mais discreta pelo narrador, o qual sinaliza a autorização da cobrança do pênalti por meio de duas onomatopeias "Prrrrii!" "Pan!" (MACHADO, 2012, p.45), podemos afirmar que este é bem mais detalhado que o gol do time alviverde, visto que o interlocutor da obra, por meio da manifestação da torcida do Palestra, deve fazer as devidas inferências para construção do sentido do gol.

É bem verdade que, materializado em texto literário, não se pode ouvir a entonação da narração radiofônica ${ }^{6}$ empregada pelo narrador para conduzir o conto na voz desse narrador. No entanto, algumas marcas linguísticas presentes no conto evidenciam que esse enunciador abre espaço para a torcida corintiana expressar sua euforia, como podemos observar a partir dos seguintes fragmentos: "-Gooool! Gooool! [...] Palhetas subiram no ar. Com os gritos. Entusiasmos rugiam. Pulavam. Dançavam. E as mãos batendo nas bocas: -G-o-o-o-o-o-o-ol!"( MACHADO, 2012, p.42). “- Gooool! Gooool! [...] - Aleguá-guá-guá! Hurra! Hurra! Corinthians! [...] Solt'o rojão! Fiu! Rebent'a bomba! Pum CORINTHIANS!" (MACHADO, 2012, p.45).

Tanto no primeiro quanto no segundo excerto acima, instiga-nos a tamanha euforia da torcida do Corinthians expressamente aberta pelo narrador por meio do discurso direto. Expliquemos: a partida ocorre no estádio do Palestra, onde há, como de costume nos jogos futebolísticos, uma concentração maciça dos torcedores do time da casa. Desse modo, os torcedores da equipe visitante - nesse caso, os corintianos - constituem apenas uma pequena parcela das arquibancadas, o que não justifica a tamanha exaltação. Assim, entendemos que o narrador, fazendo uso da prerrogativa que the é atribuído enquanto instância ficcional, prefere enfatizar, abertamente, os lances corintianos, dando ênfase à vibração dessa torcida, em detrimento da tênue descrição que reserva aos momentos palestrinos, cujo gol e a exaltação destes torcedores estão situados na periferia da narração, ainda que estes estejam em maior número do estádio, conforme demonstra o fragmento abaixo:

\footnotetext{
${ }^{6}$ A partir da leitura do conto é possível constatar, logo de antemão, que autor apropria-se do gênero narração esportiva radiofônica para conduzir toda a trama, pois, a partir de uma leitura mais acurada, nota-se que a referida narração apresenta todas as regularidades que competem a esse textoenunciado.
} 
Centra, Matias! Centra, Matias!

Matias Centrou. A assistência silenciou. Imparato emendou. A assistência silenciou. Imparato emendou. A assistência berrou.

- Palestra! Palestra! Aléguá-guá! Palestra! Aleguá! Aleguá! (MACHADO, 2012, p.43).

Em consonância aos postulados de H. Fielding, Arrigucci Jr. (2008) postula que um escritor não deve poupar esforços para descrever uma cena em potencial. Isso significa, em nossa compreensão, que uma ação, já descrita no corpus da obra, possui elementos que são de interesse daquele que enuncia. Pressupomos, assim, que as cenas que se remetem às torcidas de ambos os times constituem um ato proposital do enunciador que, por algum motivo, quis apresentar, aos leitores, uma torcida (corintiana) alegre, que sabe se comportar à beira do gramado, enquanto os torcedores palestrinos são retratados, por ele, de maneira negativa, pois, diante de vinte mil pessoas na arquibancada e um jogo ocorrendo dentro das quatro linhas, o narrador focaliza a cena em que é apresentada a confusão desses torcedores com a polícia:

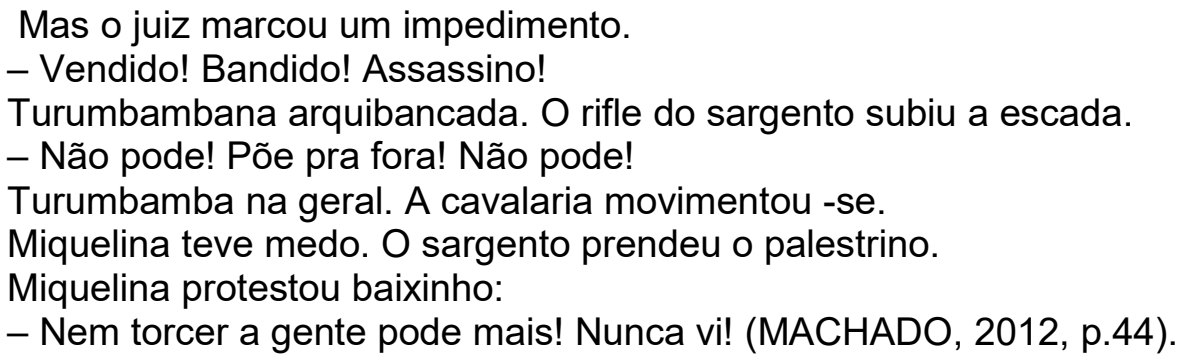

A partir desse raciocínio, somos levados a desconfiar desse narrador que, pelo menos à primeira vista, apresenta-se como torcedor do Corinthians. Ademais, não podemos esperar imparcialidade desse sujeito que não mede o seu tom para narrar uma partida de futebol. É o caso do personagem responsável pela condução da trama de $A$. Machado, que não se intimida em apresentar, ainda, vocativos como: "Aí, Biagio, Assim, Biagio, Isso!, Salame nele, Biagio" (MACHADO, 2012, p.45, grifo nosso), permitindo que nós, leitores, observemos o seu incentivo para com o time do Corinthians, na condição de torcedor, ou melhor, como

[...] espectador que 'co-atua' motoramente, de forma intensa, como se pudesse contribuir, com sua conduta aflita, para o sucesso de sua equipe, o que ele, enquanto 'torcida'- como massa de fanáticos que berram -, realmente faz (ROSENFELD, 1993, p. 94). 
Embora tenhamos tomado as considerações teóricas de Friedman e as proposições críticas de Arrigucci Jr. como respaldo para esta análise, é-nos válido e necessário, para endossar nossa tese, recorrermos à noção de "autor implícito", proposta pelo crítico norte-americano Wayne Booth, o qual, na obra Retórica da Ficção (1980), afirma que esse "autor" interpõe-se como sujeito intermediário de uma história, envolvendo toda a narrativa e eliminando qualquer possibilidade de imparcialidade.

Booth (1980) afirma, ainda, que, tanto em uma narrativa em primeira pessoa quanto em terceira pessoa, toda a história é perpassada pela consciência do autor real, que dá vida ao "autor implícito" e ao próprio narrador, mascarando-se por trás dessas figuras ou de outras vozes que possam representá-lo no plano diegético. Nas palavras de Wayne,

Enquanto escreve, o autor não cria, simplesmente, um "homem em geral", impessoal, ideal, mas sim uma versão implícita de "si próprio", que é diferente dos autores implícitos que encontramos nas obras de outros homens [...] Quer adotemos para este autor implícito a referência "escriba oficial", ou o termo recentemente redescoberto dor Kathleen Tillotson - o "alter ego" do autor - é claro que aquilo de que $o$ leitor se apercebe nesta presença são os efeitos mais importantes do autor. Por impessoal que ele tente ser, o leitor construirá, inevitavelmente, uma imagem do escriba oficial que escreve desta maneira - e, claro, esse escriba oficial nunca será neutral em relação a todos os valores. A nossa reação a seus vários compromissos, secretos ou a ser descobertos, ajudará a determinar a nossa resposta à obra (BOOTH, 1980, p.88, grifo nosso).

Diante do exposto, é-nos claro que o teórico compreende o autor implícito como sendo elemento fictício, uma versão do autor real. No entanto, é preciso atentar para a ênfase que Booth afere à natureza comprometida desse sujeito, pois, ainda que este seja um recurso ficcional, salienta o crítico americano que ele não deixa, em hipótese alguma, de manifestar determinados compromissos do autor real.

Compreendida, pois, a noção de autor implícito, entendemos que Alcântara Machado, autor real, faz-se presente de maneira implícita em seu conto por meio da figura do narrador que, como vimos anteriormente, conduz tendenciosamente o enredo, pois o escritor modernista foi 
Machado de Oliveira - um grande incentivador desta paixão, podendo vê-lo ser nomeado Presidente Honorário do Corinthians, além da homenagem recebida com o direito de dar o pontapé inicial no jogo comemorativo de inauguração do primeiro estádio do Clube na Ponte Grande, em 1918, estádio este que só foi possível concretizar sua existência através do poder político exercido por ele (GARCIA, 2010, p.01).

Em sua considerável produção literária, Machado poderia ter criado narradores que pudessem conduzir o enredo de qualquer jogo de futebol, entre qualquer equipe, mas decide, pela razão de ser corintiano, dar vida a um narrador que se encarregou de narrar a partida de seu time, mais precisamente o jogo em que o Corinthians vence seu arquirrival dentro de sua própria casa. Esse narrador, sujeito nada confiável para tal empreitada, limita-se a detalhar algumas cenas das jogadas alviverdes - como o gol, por exemplo - porque, na condição de torcedor, interessa-lhe mais as ações/jogadas de sua equipe.

Não nos esqueçamos de que o narrador se apropria de uma linguagem utilizada em narrações radiofônicas para narrar à partida de futebol, a qual exige, via de regra, "uma precisão e uma rapidez na divulgação dos acontecimentos" (SILVA, 2010, p.64). Essa linguagem, situada na esfera jornalística, conta com determinadas regras como a objetividade, a clareza e a imparcialidade. As duas primeiras regras são uma constante na obra analisada, uma vez que o texto "é fundamentalmente visual. É quase só imagem, movimento e ruído. Verbos, interjeições e onomatopeia" (SEVCENKO, 1994, p.32). O mesmo não podemos falar da imparcialidade, visto que a torcida do narrador para com o seu time está diluída no tom da narração, ou seja, em sua na entonação, pois ora vibra por meio da voz do torcedor ("Goool, Goool, Go-o-o-o-o-ol"), ora ironiza o Palestra por meio de sua própria voz: "Salame nele, Biagio".

\section{Considerações Finais}

Mediante a impossibilidade de narrar após as diversas transformações pelas quais passaram a humanidade e narrativa - a grande Guerra e a ascensão do gênero romance, por exemplo, que inviabilizaram o intercâmbio de experiências podemos concluir que o estudo do conto, na perspectiva em que nos propusemos a analisar, permitiu-nos compreender o quão problemático e polêmico são as questões concernentes ao narrador ainda hoje. Mais do que isto, o estudo também nos 
possibilitou entender, em certa medida, a constituição estrutural do texto, cujo autor materializa a narração radiofônica em construção literária, pois "essa é uma escrita de ênfase física, voltada para os sentidos, os nervos e os músculos, não mais para o intelecto, a sensibilidade e os sentimentos" (SEVCENKO, 1994, p. 32). Nesse sentido, o autor do conto vai ao encontro das inovações modernistas, uma vez que estas, como reitera Bosi (2006, p. 369), "atingem vários estratos da linguagem literária".

Brasileiro apaixonado, Alcântara Machado deixou-se levar, como muitos brasileiros, pelo encantamento da prática do futebol. Não há como negar que o seu envolvimento com o esporte tenha influenciado em sua produção literária. Tanto o é que o seu Sport Clube Corinthians Paulista, como pontua Garcia (2010), foi representado, à sua maneira, em Corinthians (2) VS. Palestra (1), permitindo que nós, neste trabalho, conduzíssemos uma leitura amparada em alguns pressupostos teóricos, sem a pretensão de esgotar o assunto, pois, os textos literários - ainda mais os dessa natureza - estão sempre abertos a outras possibilidades interpretativas.

\section{Referências}

ADORNO, T. Posição do narrador no romance contemporâneo. In: ADORNO, T. Notas de literatura I. Trad. Jorge de Almeida. São Paulo: Duas Cidades; Editora 34, 2003. p. 55-63.

ARRIGUCCI JR., D. Teoria da narrativa: posições do narrador. Jornal de Psicanálise, v.31, n. 57, p. 9-43, 1998.

BENJAMIN, W. O narrador: considerações sobre a obra de Nikolai Leskov. In: BENJAMIN, W. Magia e técnica, arte e política: ensaios sobre literatura e história da cultura. São Paulo: Brasiliense, 1994, p. 197-221.

BOSI, A. História concisa da literatura brasileira. São Paulo: Cultrix, 2006.

BOOTH, W. A retórica da ficção. Trad. Maria Teresa H. Guerreiro. Lisboa: Arcádia, 1980.

COSTA, F. O futebol na ponta da caneta. Revista USP, n. 22, 1994. Disponível em: http://www.revistas.usp.br/revusp/article/view/26961/28739. Acesso em: 14 dez. 2018. 
DALCASTAGNĖ, R. Contas a prestar: o intelectual e a massa em A hora da estrela, de Clarice Lispector. Revista de crítica literária latinoamericana. Lima-Hanover, n.51, p. 83- $98,2000$.

DAMATTA, R. Antropologia do óbvio: notas em torno do significado social do futebol. Revista USP, n. 22, 1994. Disponível em: http://www.revistas.usp.br/revusp/article/ view/26954/28732. Acesso em: 14 dez. 2018.

FRIEDMAN, N. O Ponto de vista na ficção: O desenvolvimento de um conceito crítico. Trad. Fábio Fonseca de Melo. Revista USP, n.53, p.166-152, 2002. Disponível em: https://www.revistas.usp.br/revusp/article/view/33195/35933. Acesso em: 14 dez. 2018.

GARCIA, L. Corinthians (2) VS Palestra (1) e Gaetaninho: posições interpretativas do futebol nos contos do corintiano Antônio de Alcântara Machado. Anais do Silel, v.2. n.2. Uberlândia, MG: EDUFU, 2010. Disponível em: http://www.ileel.ufu.br/ anaisdosilel/pt/arquivos/silel2011/1011.pdf. Acesso em: 14 dez. 2018.

GUTERMAN, M. O futebol explica o Brasil. São Paulo: Contexto, 2009.

MACHADO, A. Contos Paulistanos. São Paulo: Editora UNESP, 2012.

ROSENFELD, A. Negro, macumba e futebol. São Paulo: Perspectiva, 2007.

ROSSUN-GUYON, F. van. Ponto de vista ou perspectiva narrativa. In: VANROSSUN-GUYON, F.; HAMON, Ph.; SALLEN, D. Categorias da narrativa. Lisboa: Vega, [1976].

SEVCENKO, N. Futebol, metrópoles, desatinos. Revista USP, n. 22, 1994. Disponível em: http://www.revistas.usp.br/revusp/article/view/26956/28734. Acesso em: 14 dez. 2018.

SILVA. E. Narração esportiva no rádio: subjetividade e singularidade do narrador. São Paulo: Eccon, 2010. 